\title{
Financial Burden of Unnecessary Test Request for Thyroid Tests in Public Health Laboratory: To What Extent the Algorithms are Used?
}

\author{
Durmuş Ayan
}

Amasya University Sabuncuoglu Serefeddin Research and Training Hospital, Amasya Central Public Health Laboratory, Amasya, Turkey

\section{ABSTRACT}

Objectives: In this study, we aimed to investigate the financial burden of not performing thyroid function tests (TFT) according to the algorithms in diagnosis and treatment guidelines.

Methods: The TFT results of 61.422 patients whose testing was requested between 01.01.2018-31.12.2018 in Amasya Public Health Laboratory were analyzed retrospectively. The results of the patients were grouped according to the diagnoses specified in the diagnosis and treatment guidelines (euthyroid, hyperthyroid and hypothyroid). In addition, patients were grouped according to the type of test request (group 1: Thyroid stimulating hormone (TSH), group 2: TSH and free triiodotyronine (fT3), group 3: TSH and free throxine (fT4), group 4: TSH, fT4 and fT3).

Results: Among these patient results, the number of patients who received TSH only in the first step, in line with the algorithms, was 12.522 (20.2\%). The number of the patients from whom TSH and fT 3 were requested together was identified as $703(1.1 \%)$, fT4 and TSH together as 6343 patients (11.2\%) and all three tests (TSH, fT4 and fT3) as $41.854(67.5 \%)$. The total cost of the test requests was calculated as 388.426 Turkish Liras per annum, which was repaid to institutions in accordance with the principles of Health Practice Communiqué.

Conclusion: According to the results we obtained, it was found that the algorithms related to the request of thyroid tests were not followed, and the financial implications of this situation were high. We believe that the inclusion of applications, such as reflex testing in laboratory automation and planning of training for algorithms, will reduce improper test requests and unnecessary financial burden.

Keywords: Thyroid gland, thyroid diseases, thyroid function test

\section{INTRODUCTION}

Thyroid dysfunction is very common in the population and thyroid function tests (TFT) are of the frequently requested tests within the hormone panel. Thyroid-stimulating hormone (TSH), free triiodothyronine (fT3) and free thyroxine fT4) tests are used to evaluate thyroid functions. ${ }^{[1]}$ Although it may seem useful to measure both TSH and fT4 for the diagnosis of thyroid dysfunction, even small changes in fT4 levels may cause very large changes in TSH levels. ${ }^{[1,2]}$ Therefore, most guidelines and algorithms propose a two-step approach (thyroid cascade) in the TFT request. In this two-step approach, after TSH measurement is performed, if the TSH result is outside the reference range, then, $\mathrm{fT} 4$ measurement is recommended. ${ }^{[3-7]}$

Although there are algorithms and guidelines for requesting these tests, in general, usually, all three tests are requested in combination, which leads tomany unnecessary financial burden. ${ }^{[1,8,9]}$ Studies have found that TSH has higher sensitivity and specificity compared to other tests in cases of thyroid dysfunction (hypothyroidism and hyperthyroidism). ${ }^{[7]}$ 


\section{METHOD}

TSH, fT3 and fT4 tests of patients aged 18-65 years $(n=61.422)$ who were accepted to Amasya Central Public Health Laboratory between 01.01.2018-31.12.2018 were retrospectively analyzed and included in this study; patients with positive pregnancy test were excluded from this study. In this study, the first group consisted of patients for whom only TSH was requested. The second group included patients for whom only fT4 and TSH, the third group included patients for whom only fT3 and TSH, and the fourth group included patients for whom all three of fT4, fT3 and TSH were requested. In addition, patient groups were evaluated by being grouped as euthyroid, hypothyroidism and hyperthyroidism according to their clinical diagnoses (Table 1). TSH, fT3 and fT4 tests were performed by electrochemiluminescence method in module e601 of Roche Cobas 6000 . Reference ranges of tests were TSH (0.27-4.2 $\mu \mathrm{IU} /$ $\mathrm{mL})$, fT3 (2.0-4.4 pg/mL), fT4 (0.93-1.7 ng/dL). Unnecessary test request procedure was applied for groups except for the TSH alone group (group 1), which were the $2^{\text {nd }}$ Group, $3^{\text {rd }}$ Group and $4^{\text {th }}$ Group. Tests other than the TSH test in these groups were considered unnecessary test requests. In the cost analysis of the impact on health expenditures, the unit price of TSH, fT3 and fT4 was determined as 4.28 Turkish Liras (TL), based on the updated 2013 Health Practices Communiqué (HPC) with the 01.02.2019 amendment request entered. The total cost was calculated by multiplying the specified unit price with the number of tests in the groups where unnecessary test request is thought to have been made.

\section{Statistical Methods}

For the statistical analysis, SPSS 15 for windows version was used. Descriptive statistics were presented for as number and percentage.

\section{RESULTS}

At the end of our retrospective analysis, we reached the number of 61.422 patients recorded in the system with the TFT requests. Among these patient results, the number of the patients who were requested only $\mathrm{TSH}$, in accordance with the algorithms, was 12.522 (20.2\%); the number of the patients who were requested fT3 and TSH together was 703 (1.1\%); the number of the patients who were requested fT4 and TSH was 6343 (11.2\%); and the number of the patients who were requested all three (TSH, fT4 and fT3) was 41.854 (67.5\%). In the first step, when only test requests other than TSH request are considered unnecessary, costs were 3.008 TL for fT3 and TSH request, 27.148 TL for fT4 and TSH and 358.270 TL for fT3, fT4, while the total cost of the unnecessary test request to our laboratory was found to be $388.426 \mathrm{TL}$ per year as the monetary financial equivalent of reimbursement to the institutions according to the HPC principles.

\section{DISCUSSION}

In this study, the extent to which the correct test request procedures are applied in the algorithms specified in the thyroid guidelines and the financial burden of the unnecessary test requests of the samples that the correct test request procedure was not applied are investigated. According to the results, it was determined that the correct test request procedures in the algorithms specified in the guidelines were applied only at a $20.2 \%$ rate. In addition, the monetary financial equivalent of reimbursement to the institutions according to the HPC principles for the unnecessary tests on samples not conforming to the correct test request procedures laid out in the thyroid guidelines and algorithms was found to be 388.426 TL per year.

As stated in the diagnostic guidelines, it is generally recommended to use $2^{\text {nd }}$ and $3^{\text {rd }}$ generation methods in the laboratories to have high sensitivity and specificity of the TSH test, which should be measured in the first step. [7, 10-12] In studies with outpatients with no expectancy of pituitary/hypothalamic disease, it is often stated that it is usually unnecessary to measure fT4 when TSH is normal. ${ }^{[7,13]}$ Therefore, when performing TFT measurement, it is recommended by the thyroid guides that only the TSH measurement should be performed in the first step and

Table 1. Thyroid disorder rates according to the test request procedure

\begin{tabular}{|c|c|c|c|c|}
\hline & $\begin{array}{c}\text { Group } 1 \\
\text { (TSH) }\end{array}$ & $\begin{array}{c}\text { Group } 2 \\
\text { (fT4+TSH) }\end{array}$ & $\begin{array}{c}\text { Group } 3 \\
\text { (fT3+TSH) }\end{array}$ & $\begin{array}{c}\text { Group } 4 \\
\text { (fT3+fT4+TSH) }\end{array}$ \\
\hline Euthyroid & $10.526(84.1)$ & $5022(79.2)$ & $692(98.4)$ & 38.080 (90.9) \\
\hline Hyperthyroid & $1135(9.0)$ & $580(9.1)$ & $3(0.5)$ & $151(0.4)$ \\
\hline
\end{tabular}


that fT4 measurement should be performed in the second step (using 2-step thyroid cascade) if the TSH measurement is out of the specified reference range. ${ }^{[1]}$ Therefore, TSH measurement is very important given that TSH measurement decides how the thyroid measurement cascade will progress in this case.

In previous studies, it was found that TFT were performed in compliantly with the algorithms and unnecessary test request rate was high. Demirci et al.investigating the suitability of diagnostic algorithms have reported the rate of inappropriate test requests for internal polyclinics as 40.6\%; for all non-internal clinics as 52.4\%; Yıldırmak et al. reported the same as $36.6 \%$, and Tekçe et al. as $76 \%$. In our study, the rate of inappropriate test requests for TFT tests was $79.8 \% .^{[8,9,14]}$ Such unnecessary requests of the tests lead to an increase in laboratory load and loss of time as well as an unnecessary increase in financial burden. It is quite difficult to change existing habits regarding the test request. Test requests made according to guidelines and algorithms should be used effectively to reduce costs and achieve an accurate clinical diagnosis of the disease. In this way, health expenditures will be positively contributed as well as reliable diagnostic methods will be supported with reliable results. Kim et al. reported that instead of the classical algorithm, the addition of quick-pick procedures to the test selection program in accordance with the rules specified in the guidelines reduced the unnecessary test requirement by $50 \%{ }^{[15]}$ The use of quick-pick test procedures by clinicians according to reflex test rules can prevent both confusions when making a test request and unnecessary testing. If certain test panels are identified and used according to the priorities specified in the guidelines, the applicability of the algorithm may become more effective and practical for the clinician. Demirci et al. found that the unnecessary test request decreased significantly when the reflex test was started and interpreted the decrease in the unnecessary test request, especially in the units where the TFT request was intensified, such as internal diseases, as a change in the traditional habits. [9] Gilmour et al. reported that the incidence of inappropriate test requests for TFT decreased by $49 \%$ with the switch to reflex testing. ${ }^{[16]}$

A study reported that $46 \%$ of fT4 and TSH (2-step test request) requests were performed together. ${ }^{[17]}$ Another study found that the rate of 2 -step testing was $47 \% \cdot{ }^{[18]}$ This rate was found to be $11.2 \%$ in our study. The low rate compared to other studies is generally attributable to the higher rate of all three tests being requested together (TSH, fT4 and fT3: $67.4 \%)$.

\section{CONCLUSION}

According to the results we obtained, it was found that the algorithms related to the request of thyroid tests were not followed and the financial implications of this situation were high. We believe that the financial burden will be reduced by the use of applications, such as reflex testing to reduce unnecessary test requests, informing about the algorithms specified in the guidelines, and widespread implementation of test requests in an accurate and effective manner.

\section{Disclosures}

Ethics Committee Approval: This study was approved by the Nigde Ömer Halisdemir University Faculty of Medicine Ethics Committee (No: 2020/04 Date:25 Jun 2020). This study was conducted in accordance with the Declaration of Helsinki.

Peer-review: Externally peer-reviewed.

Conflict of Interest: None declared.

\section{REFERENCES}

1. Schneider C, Feller M, Bauer DC, Collet T-H, da Costa BR, Auer $R$, et al. Initial evaluation of thyroid dysfunction - Are simultaneous TSH and fT4 tests necessary? PLoS ONE 2018;13: e0196631.

2. Hadlow NC, Rothacker KM, Wardrop R, Brown SJ, Lim EM. The relationship between TSH and free T4 in a large population is complex and nonlinear and differs by age and sex. J Clin Endocrinol Metab 2013;98:2936-43.

3. Ladenson PW, Singer PA, Ain KB, Bagchi N, Bigos ST, Levy EG, et al. American Thyroid Association guidelines for detection of thyroid dysfunction. Arch Intern Med 2000;160:1573-5.

4. Baskin HJ, Cobin RH, Duick DS, Gharib H, Guttler RB, Kaplan $\mathrm{MM}$, et al. American Association of Clinical Endocrinologists medical guidelines for clinical practice for the evaluation and treatment of hyperthyroidism and hypothyroidism. Endocr Pract 2002;8:457-69.

5. Garber JR, Cobin RH, Gharib H, Hennessey JV, Klein I, Mechanick Jl, et al. Clinical practice guidelines for hypothyroidism in adults: cosponsored by the American Association of Clinical Endocrinologists and the American Thyroid Association. Endocr Pract 2012;18:988-1028.

6. LeFevre ML; U.S. Preventive Services Task Force. Screening for thyroid dysfunction: U.S. Preventive Services Task Force recommendation statement. Ann Intern Med 2015;162:641-50.

7. Biondi B, Bartalena L, Cooper DS, Hegedüs L, Laurberg P, Kahaly GJ. The 2015 European Thyroid Association Guidelines on Diagnosis and Treatment of Endogenous Subclinical Hyperthyroidism. Eur Thyroid J 2015;4:149-63.

8. Kın Tekçe B, Dikbas O, Tekçe H, Tosun M. Evaluation of the Requests for Thyroid Function Test According Algorithms and 
Cost Effectivity. Abant Med J 2013;2:114-8.

9. Demirci F, Karakoyun I, Duman C, Arslan FD, Özbek D, Kalenci D. Tiroid Fonksiyon Test İstemlerinde "Refleks Test" Uygulaması ve Sağlık Harcamalarına Etkisinin İncelenmesi. Türk Klinik Biyokimya Derg 2017;15:67-74.

10. De Los Santos ET, Mazzaferri EL. Sensitive thyroid-stimulating hormone assays: clinical applications and limitations. Compr Ther 1988;14:26-33.

11. de los Santos ET, Starich GH, Mazzaferri EL. Sensitivity, specificity, and cost-effectiveness of the sensitive thyrotropin assay in the diagnosis of thyroid disease in ambulatory patients. Arch Intern Med 1989;149:526-32.

12. Surks MI, Chopra IJ, Mariash CN, Nicoloff JT, Solomon DH. American Thyroid Association guidelines for use of laboratory tests in thyroid disorders. JAMA 1990;263:1529-32.

13. Viera AJ. Thyroid function testing in outpatients: are both sensitive thyrotropin (sTSH) and free thyroxine (FT4) necessary? Fam Med 2003;35:408-10.
14. Yıldırmak SY, Usta M, Emecen Ö, Dikbaş O. Appropriateness of Thyroid Function Test Requesting to the Foreseen Algorithm in Giresun Province Center. Journal of Turkish Clinical Biochemistry 2017;15:114-8.

15. Kim JY, Dzik WH, Dighe AS, Lewandrowski KB. Utilization management in a large urban academic medical center: a 10-year experience. Am J Clin Pathol 2011;135:108-18.

16. Gilmour JA, Weisman A, Orlov S, Goldberg RJ, Goldberg A, Baranek $\mathrm{H}$, et al. Promoting resource stewardship: Reducing inappropriate free thyroid hormone testing. J Eval Clin Pract 2017;23:670-5.

17. Services. TNAoViD. Reducing unwarrented variation to increase value and improve quality. RighCare. http://fingertipspheorguk/documents/Atlas_2013\%20Diagnosticspdf. November 2013.

18. Emerson JF, Emerson SS. The impact of requisition design on laboratory utilization. Am J Clin Pathol 2001;116:879-84. 